\title{
UNA MIRADA DESDE LA PERSPECTIVA SOCIO-HISTÓRICA AL ROL DE LA MUJER EN LA FORMACIÓN EDUCACIONAL EN LOS COLEGIOS
}

\section{A Look from the Socio-Historical Perspective to the Role of Women in Educational Training in Protestant Schools}

\author{
Libia Janei Thaureaux Vives, MsC. \\ Universidad de Oriente, Cuba \\ https://orcid.org/0000-0002-5072-159X
}

libiaj@uo.edu.cu

Palabras claves: Protestantismo, Rol de la Mujer, Formación Educacional.

Keywords: Protestantism, Role of Women, Educational Formation.
Recibido: 31 de agosto de 2020

Aceptado: 19 de noviembre de 2020

\section{RESUMEN}

La investigación constituye una aproximación desde la perspectiva socio-histórica, a la labor desarrollada por las mujeres cristianas en la formación educacional dentro del protestantismo cubano, específicamente en los colegios protestantes de tradición Bautista, los cuales tuvieron una influencia positiva en la sociedad cubana y en gran parte de la región oriental. Los principales resultados revelan la influencia de estos colegios protestantes en la sociedad cubana, así como la labor que las mujeres desarrollaron en la enseñanza educacional, y como estas inculcaron a través de su fe religiosa valores patrios y morales en las jóvenes generaciones.

\section{ABSTRACT}

An analysis has been made about de role played by Christiam women in the educational formation within the Cuban Protestantism from a historical and social perspective, specifically in the protestant schools of the Baptist tradition which had a positive influence on Cuban society and in a great part of eastern region. The main results prove the influence that protestant schools had on Cuban society so as the role played by Christian women in the educational process and how they fostered their religious faith in the formation of patriotic valves of young generations. 


\section{INTRODUCCIÓN}

En la investigación en la que nos adentramos, se analiza los avances del protestantismo como sistema religioso que cambio notablemente la vida de hombres y mujeres, y que por tanto defiende un profundo respeto por la libertad individual. Todo ello, permite aseverar que la labor que desplegaron incidió en una nueva forma de vivir la fe y la espiritualidad.

Sobre la situación de la mujer en los diferentes ámbitos de la vida social se ha escrito múltiples investigaciones desde diferentes perspectivas de análisis. En un recorrido socio histórico, de la temática, nos hemos encontrado un artículo de la autora Raquel Vinat de la mata "¿Reinas del Hogar? Mujeres en las unidades familiares cubanas del siglo XIX”, la cual sostiene la idea de que: "la presencia femenina en las relaciones patriarcales del siglo XIX deja ver las marcas de la desvalorización hacia la mujer, de su condición de subalterna en los espacios públicos y familiar."

Esto nos da la medida que la posición de la mujer, frente a las diferentes áreas de la estructura social era completamente inferior, no se establecían excepciones en cuanto a la raza, posición económica o religión, etc. Si no que se establecía como una regla: que fuese considerada como un instrumento que influía de una manera decisiva en el crecimiento demográfico de la población, siendo catalogada como un objeto sexual con el único fin de reproducir y mantener la especie, así como velar por la educación de los hijos; en tanto que la posición del hombre con respecto a la mujer frente al matrimonio era más favorable, obteniendo de ello un estado relevante a nivel social y por ende su realización como ser humano.

Es importante abordar que, al analizar la situación de la mujer en el ámbito familiar y social, no podemos deslindar el contexto histórico en el que se desarrollan los procesos, de modo que en el siglo XIX e inicios del siglo XX, el tipo de familia que imperaba en la sociedad cubana, era el tipo de familia patriarcal, ya que heredamos el modelo europeo donde las relaciones familiares y sociales giraban en torno a la figura paterna, caracterizándose estas por ser rígidas y cerradas. En la presente se valora desde una perspectiva socio-histórica al rol de la mujer en la formación educacional en los colegios protestantes, a partir de la utilización de importantes métodos de investigación como: la sistematización, histórico lógico, entrevistas, testimonios y análisis de documentos relacionados con el tema.

\section{DESARROLLO}

Este importante estudio, nos deja ver que las primeras propuestas en el campo educativo de la mujer, se iniciaron educando a las mujeres de clase alta y los primeros centros de cultura fueron los conventos; allí ellas aprendían a leer, escribir, coser, así como desempeñar otras artes domésticas, también era importante que tuviesen conocimiento de música y por supuesto dominar algún instrumento musical. Esta educación se fue extendiendo de manera muy lenta hacia mujeres de clases populares por algunas señoras que recibían en sus casas a un grupo de niñas o jóvenes, consistía básicamente en enseñar las labores propias de la casa.

Luego, de los progresos del Protestantismo, que influyeron de una manera decisiva en el ámbito familiar y eclesial, producto de las constantes transformaciones que a nivel macro social se venían gestando, esto produjo que la mujer alcanzara un mayor reconocimiento a nivel social y familiar, aunque las que pertenecían a la clase aristocrática y que se mantenían bajo el respaldo económico de sus esposos siguieron arraigadas a las férreas concepciones de la clase dominante, hallándose en la paradoja de tener ansias de libertad, aunque su pensamiento conservador era mucho más fuerte, de modo que, la mayoría estudiaban pero sólo como una posibilidad para potenciar el nivel cultural de sus hijos, sintiéndose ellas realizadas en el ámbito hogareño.

\section{La impronta de los colegios protestantes en la sociedad}

Específicamente, en la región santiaguera existían centros de enseñanza, con un notable prestigio, como el instituto de segunda enseñanza (1864); el colegio Dolores (1913); la escuelita Spencer para niñas, sin embargo, muchas estuvieron influenciadas por concepciones y pensamientos retrógrados, dígase que la mujer es creada por Dios para la reproducción solamente y el cuidado de los hijos, que es bueno ante Dios la realización de votos de castidad, por lo que muchas tuvieron que enclaustrarse en conventos, dedicarse al cuidado de enfermos en hospitales, velar por la educación de la mayoría de la población, y la atención de la comunidad religiosa, sobre todo en la liturgia para que todo estuviese en orden para la celebración de la misa católico romana.

La entrada de las iglesias de tipo protestante en el contexto nacional, cambió un tanto la posición de la mujer frente a la vida social y eclesial, podemos expresar que entre las más influyentes se encuentran los Bautistas, los Metodistas, los Episcopales, y los Presbiterianos; en sus inicios estuvo acompañado de la creación de espacios educacionales, 
que asumían una pedagogía norteamericana con todo lo que ello representa, jugaron un papel importante en la educación de toda la población a nivel nacional y específicamente en la región oriental, notorio sería enfatizar que la educación ha desempeñado un papel dominante en la construcción social, pues las sociedades han utilizado la educación como herramienta para la transmisión o adelanto de la cultura, la enseñanza de los patrones de conductas aceptables, y la búsqueda constante de conocimientos, valores, destrezas y actitudes, por medio de instituciones que han sido creadas con ese fin.

La educación cristiana está más ligada a la formación integral del creyente, a la instrucción eclesial y al crecimiento espiritual del ser humano, para que se manifieste una fe comunitaria que transforme, por tanto, a su vez, a la sociedad.

Entre los colegios que gozaron de gran prestigio están: la Escuela Progresiva, de los Presbiterianos, en Cárdenas en la Provincia de Matanzas, el Candle College de los metodistas, en la Habana, el colegio Pinson también de los metodistas en Camagüey, y los Colegios Internacionales del Cristo de los Bautistas y uno más pequeño y modesto, pero igualmente eficaz en la formación intelectual y moral de la juventud, el colegio Instituto Martí en Santiago de Cuba.

La historia atesora el primer curso de los Colegios Internacionales, que se inició el lunes 9 de septiembre de 1907, bajo la dirección de Alfredo L. Story Betancourt , este centro educacional ofrecía educación a los padres de familia para que sus hijos cursaran la primera y segunda enseñanza, el claustro estaba compuesto por profesores de diversos países, Estados Unidos, España y también cubanos, se les prestaba especial atención a los cursos de música, pintura y también se priorizaba la enseñanza del idioma inglés, como en el Instituto Martí.

La misión de estos colegios internacionales se hace evidente al expresarse: ... "Nuestro deseo es ofrecer al público en general ya los miembros de nuestras iglesias en particular, un colegio donde las fuerzas intelectuales, físicas y morales de nuestros alumnos sean debidamente desarrolladas. Al estar el colegio establecido por la Sociedad Bautista, el espíritu de libertad de conciencia, que es una de las bases fundamentales de su creencia, será incluido en su grado más alto, dando así plena libertada para alumnos de toda idea religiosa".

Al remontarnos en la historia, los actos de inauguración oficial de los colegios internacionales del Cristo, fundado por The American Baptist Home Mission Society of New York, se efectuaron el miércoles 5 de febrero de 1908, con once bautizos, acto significativo de rotura de la tierra para la construcción del nuevo templo bautista en el poblado, y en la noche el acto oficial con discursos de educación cristiana, música religiosa y mensajes evangélicos propio del protestantismo histórico.

Para lograr una mejor comprensión del funcionamiento del Instituto Martí, se entrevistó al Reverendo Joel Rosales Cortés, el cual abordó que se debe hacer una división en dos períodos, el primero de 1900 hasta el año 1931 cuando se produce por la crisis machadista la clausura temporal del colegio, es de gestación y crecimiento del instituto, resultó muy importante pues fue atendido especialmente por las misioneras norteamericanas que venían a trabajar como maestras. El segundo, se extiende de 1937 cuando se reabre el colegio hasta 1957, tiempo considerado como la edad de Oro del Instituto Martí, para este tiempo ya la institución educativa se consolida y es dirigida por eminentes y enérgicos educadores santiagueros.

En la década del cincuenta un número considerable de maestras le dieron gran prestigio al Instituto Martí, éstas se encargaban de garantizar una formación integral a los educandos, preparándolos para la vida y para que tuvieran una influencia positiva a nivel social.

Podemos observar que no solo las mujeres ejercieron roles de maestras, aunque en nuestra investigación tratamos de resaltar la labor de estas, también se cuenta con hombres que de una forma u otra contribuyeron a la formación educacional de la población, en este sentido se puede hacer referencia a la labor desplegada por el gran líder Frank Issac País García, en el año 1952, el cual trabajó como repasador con muy buena calificación en el Instituto Martí y como maestro para el año 1954 en el Colegio el Salvador, donde se destacó por la pasión con que difundía las ideas nacionalistas, democráticas y cristianas, especialmente el pensamiento y la obra de José Julián Martí Pérez. También se tiene conocimiento otro líder Oscar Lucero Moya, considerado el Mártir del Silencio, para el período de 1948 hasta 1953 trabajó como maestro de 5to y 6to grado en el Instituto Martí.

\section{El papel de la mujer en los colegios protestantes.}

Para la realización de esta investigación fue necesario la consulta de diversas fuentes que constituyen el fundamento o base teórica del análisis histórico-lógico, por lo que desde sus comienzos, el movimiento protestante se enriqueció gracias al liderazgo y ministerio de las mujeres, quienes a menudo le enseñaron a la comunidad, cómo vivir la vida cristiana a través de la adoración en fidelidad; el estudio, la disciplina, el cuidado de los pobres, los enfermos, los 
agonizantes y los desposeídos, es decir las personas con mayor desventaja social. Con frecuencia, las mujeres también desempeñaron roles pastorales aun cuando no estaban oficialmente ordenadas.

En este sentido, muchas mujeres se desarrollaron como maestras, y por tanto, muchas de las concepciones con respecto a la mujer fueron cambiando en la medida en que la sociedad cubana iba evolucionando a raíz de las constantes transformaciones que se gestaron a nivel económico, político y social después de 1959, de acuerdo a las transformaciones en la estructura social, influyendo en todas las esferas de la vida social tanto en el ámbito privado como en el público, en el caso de las féminas les proporcionó nuevas experiencias que influyeron en la apropiación de nuevos modelos de vida, que antes habían sido un tanto vedados, ellas mismas fueron buscando su propio espacio a nivel social y familiar, ampliando su horizonte cultural, que las hacía más libre en la forma de concebir la realidad.

Seguidamente, esbozamos las mujeres que jugaron un papel fundamental, esencialmente en los colegios de la Iglesia Bautista, podemos nombrar Miss Elma G. Gowen, es la primera maestra de instrucción de carácter evangélico que vino a Cuba. Le hizo entrega de su amada escuela a la educadora Miss. Margaret Howell (1906 a 1940), estas llegaron a ocupar cargos de dirección en el Instituto Martí.

Igualmente, encontramos a Miss Isabel Waidman la cual resultó ser una buena maestra y conferenciante sólida, fue nombrada Directora del Colegio Martí en Santiago de Cuba, (de 1909 a 1925). Los nombres de las misioneras que sustituyeron a Miss Waidman fueron: Miss Florence Harrington, (1915-1916), y Miss Blas Moore, (1920-1921). Trabajó también como maestra junto con Miss Waidman y Mercedes Grane. Ella y Miss Waidman le dieron gloria y prestigio al Instituto Martí durante ese periodo. También se conoce como maestra en algún momento de este periodo a la Srta. Luisa Martínez, que trabajó en el curso 1917-1918. Es bueno notar aquí que, a partir de Miss Waidman, ya se recibían varones en el instituto Martí; anteriormente solo se recibían niñas y señoritas. Al retirarse Miss Waidman la sustituye como Directora del instituto Martí, la Srta. Juanita Barrios estuvo de 1924 hasta 1931, ella había trabajado anteriormente como maestra en los Colegios Internacionales del Cristo.

En los colegios de la Iglesia Bautista y a nivel convencional, las mujeres continuaron ejerciendo un fuerte protagonismo, podemos nombrar a Sara País de Molina, hermana mayor del líder Frank Issac País García, Doctora en Pedagogía, musicóloga y directora de Coros, tocaba varios instrumentos musicales; fue una gran líder convencional en la primera década del siglo XX hasta la década del 30 , los escritos que realizaba estaban relacionados con el entorno social y eclesial cubano de la época, la misma fue codirectora del Periódico el Mensajero, redactora encargada y traductora del Diario de Cuba, donde publicaba las lecciones dominicales internacionales que distribuye la United Press, también escribió en las revistas, La Voz Bautista, y en el propio Mensajero y algunos libros titulados "Ese divino tesoro", "Hoy es mañana" e Instrumento escogido dedicado a su padre.

La investigadora Beatriz Ferreiro en su libro "Encontrar la propia voz. Obras y autoras relevantes del protestantismo en Cuba (1902-1959), relaciona una diversidad de mujeres como es el caso de Sara País de Molina, que jugaron un papel fundamental en el panorama literario del movimiento protestante, y que por tanto, sus escritos, discursos, reflexiones calaron en los sentimientos más profundos de las jóvenes generaciones de esa época, con mayor influencia en la población evangélica, muchas de estas mujeres trataron de hacer prevalecer la voz de las que habían afrontado adversidades, cuestionamientos por hacer valer sus criterios ya no en el ámbito de lo privado sino en lo social.

Por otro lado, podemos nombrar a la exfallecida, señora Lilia Lucero, la cual se desempeñó como profesora de los Colegios Internacionales del Cristo, es considerada como una gran líder a nivel convencional, ha ocupado disimiles cargos en la Convención Bautista de Cuba Oriental, y desde el punto pedagógico contribuyó con la formación integral de un comportamiento cívico en las jóvenes generaciones, pues esto constituyó un punto clave en el magisterio protestante.

Los testimonios de hombres y mujeres entrevistados demuestran el reconocimiento que tenían de estos colegios, recuerdan con amor todas las actividades que se realizaban y vislumbran la unidad de la experiencia educativa y cristiana del claustro de maestras y maestros. Al interior de estos colegios, además de las asignaturas de rigor, se priorizaba la enseñanza bíblico-teológico, y se exaltaba el valor musical de los himnos evangélicos y las oraciones. Estos niños y jóvenes eran en consecuencia asiduos asistentes a la Escuela Dominical de la iglesia, y muchos formaron las primeras generaciones de creyentes y miembros. Las escuelas diarias fueron un puntal básico de la obra evangelística y misionera. 


\section{CONCLUSIÓN}

El movimiento protestante se extendió por todo el mundo, en la actualidad se observa un movimiento que continúa en ascenso e invita a todos, sin distinción de género, raza y condición social, a aceptar el amor de Dios a través de obras de misericordia, justicia y pretende lograr que su feligresía tenga un impacto positivo a nivel social.

Se distingue que la educación impartida por los protestantes se sujetó a planes educativos con un alto grado de humanismo, destacándose el papel de la mujer que resultó decisivo en la fundación de los colegios protestantes, y muchas alcanzaron un mayor reconocimiento en el ámbito social, familiar y eclesial; la formación que recibieron muchos jóvenes de ellas resultó clave para la educación y el aprendizaje.

Se visualiza en la actualidad que las iglesias que conforman el campo protestante, ya no cuentan con estos colegios, pero si existe una valiosa memoria histórica, que enriquece esta importante parte de la historia. Los principales líderes eclesiales se han encargado de continuar con el legado que nos dejaron los misioneros protestantes, por supuesto con la gran ayuda de las mujeres que tuvieron un rol protagónico, porque sin estas esa misión no hubiese tenido un efecto positivo en la sociedad. Observamos cómo se prioriza el trabajo docente, garantizándose la capacitación bíblicoteológica y secular con un alto protagonismo de organizaciones ecuménicas como el Centro Cristiano de Reflexión y Diálogo-Cuba (CCRD-C) en Matanzas, el Centro Memorial Martin Luther King Jr., en ciudad de la Habana, y el Centro Cristiano de Servicio y Capacitación Bartolomé Gregorio Lavastida en Santiago de Cuba.

\section{BIBLIOGRAFÍA}

1. Acosta García, Roy (2000). Tomo Il. Historia y Teología de la Convención Bautista de Cuba Oriental

2. Cepeda Clemente Rafael (1986) La herencia Misionera en Cuba. Editorial DEI (Departamento Ecuménico de Investigaciones).

3. Cepeda Rafael: Apuntes para una historia del presbiterianismo en cuba. Ediciones su Voz. JSSN 0864-0262 Permiso No. 81203/168.

4. Colectivo de autores del Instituto Pedagógico Frank País: La formación cristiana y revolucionaria de Frank País García.

5. Ferreiro García, Beatriz (2013) Encontrar la propia voz. Obras y autoras relevantes del protestantismo en Cuba (1902-1959) Editorial Caminos, La Habana.

6. Molina Rodríguez, Carlos (2013) Protestantismo en Cuba. Recuento histórico y perspectivas desde sus orígenes hasta principios del siglo XXI. Volumen 2: Visiones y perspectivas. Editorial Caminos, La Habana.

7. Ramos, Marcos Antonio: Panorama del Protestantismo en Cuba. Editorial Caribe. 1986.

8. Rosales Cortés, Joel: Bosquejo Histórico del Colegio "Instituto Martí.

9. Vinat de la Mata, Raquel: Reinas del hogar. Mujeres en las unidades familiares cubanas del siglo XIX. 